\title{
Calorimetric Determination of the Half-Life of Polonium
}

\author{
D. C. Ginnings, Anne F. Ball, and D. T. Vier
}

\begin{abstract}
The heats of radioactivity of four samples of polonium have been measured with a Bunsen ice calorimeter over a period of about seven months. With samples ranging in initial powers from 0.17 to 1.4 watts, the half-life values calculated from these measurements were found to agree within 0.1 percent, or the equivalent of 0.0003 watt, whichever was the larger. The results with the sample with the largest power gave a half-life value of 138.39 days, with an uncertainty of 0.1 percent $(0.14$ day). This is in agreement with the value of 138.3 days ( \pm 0.1 percent) reported by Beamer and Easton, who used a different calorimetric method.
\end{abstract}

\section{Introduction}

Of all published determinations of the half-life of polonium, probably the most accurate is that by Beamer and Easton $[1],{ }^{2}$ who used a calorimetric method and observed a sample for as long as 97 days. Their method consisted in measuring the temperature difference between a container with the sample of polonium and an identical container that was empty. Both containers were surrounded by an isothermal jacket, and the relation between temperature difference and power was determined by means of electric calibration experiments. The value of the half-life was found to be 138.3 days $( \pm 0.1 \%)$. A Bunsen ice calorimeter is also suitable for measuring radioactive power (and half-life) of radioactive materials. Because this method is entirely different from that used by Beamer and Easton, and because much larger samples of polonium were available, it seemed worth while to measure the half-life of several samples that were suitable for measurements with the ice calorimetèr.

The Bunsen ice calorimeter seems ideally suited for several reasons to the measurement of the heat evolved by curie or multicurie quantities of alpha, weak beta, and with modification [2], other radioactive materials. First, the heat leak is small (perhaps $0.0002 \mathrm{w}$ ). Second, the calorimeter requires very little attention during the measurements, usually a few minutes every hour or two for ice-bath replenishment. Third, no electrical or temperature measuring instruments are required because the measurement of heat requires only weighing of mercury. Fourth, the calibration factor of the ice calorimeter is a fundamental physical constant, which has been determined to about 0.01 percent by electrical calibration experiments [3].

On the other hand, the ice calorimeter in its present application has an inherent variation, or error, which is comparable with its heat leak. While this does not limit the precision of experiments involving about $1-w$ power, it would limit the precision of measurements of much smaller powers. Other ice calorimeters designed specifically for small radioactive powers [2] have proved sensitive to as little as $0.000 n 3$ w. An improved ice calorimeter has been

${ }^{1}$ Los Alamos Scientific Laboratory, University of California.

2 Figures in brackets indicate the literature references at the end of this paper. in use at the National Bureau of Standards for some time in the measurement of heat capacities at high temperatures [3]. Although this calorimeter was not intended for measurements of radioactive power, it seemed suitable for measurements on certain samples of polonium (alpha emitter) furnished by the Los Alamos Scientific Laboratory, which initially developed powers in the range of 0.17 to $1.4 \mathrm{w}$. By measuring the decay of radioactive power of a sample of polonium over time intervals comparable with its half-life, values were obtained of its half-life.

\section{Experimental Details}

The ice calorimeter used in these experiments is shown in figure 1 . It is the same calorimeter previously described [3]. An ice mantle (I) was frozen around the central calorimeter well (A) on a system of copper vanes (F) designed to increase the area of contact of the central well with the ice. The sample was suspended in the bottom of this well by a small wire that was pushed over against one side of the well by the gate $G$. The heat developed in the sample melted some of the ice, thereby decreasing the volume of the ice-water system and causing mercury to be forced into the calorimeter from beaker B. A small flow upward of dry helium in the calorimeter well was maintained to prevent condensation of water vapor from the room in the calorimeter and also to increase thermal contact between the sample and the calorimeter.

The polonium samples were sealed in glass or metal containers, which were enclosed in brass outer containers made to fit closely to the central well of the ice calorimeter. Because the radiation from polonium is essentially all of the alpha type, the containers were completely effective in converting all the radioactive energy into heat within the container. A sample was lowered into the calorimeter (with the two platinum shields above it, as described elsewhere [4]), and about 10 or $15 \mathrm{~min}$ was allowed for it to come to essentially a steady temperature, the valve $\mathrm{V}$ being open. Then the mercury meniscus was adjusted to the upper part of the scale, C, by partly evacuating reservoir $R$. Valve V was immediately closed, thereby causing the meniscus at $\mathrm{C}$ to start to move downward due to the heat input to the calorimeter. The time wa 


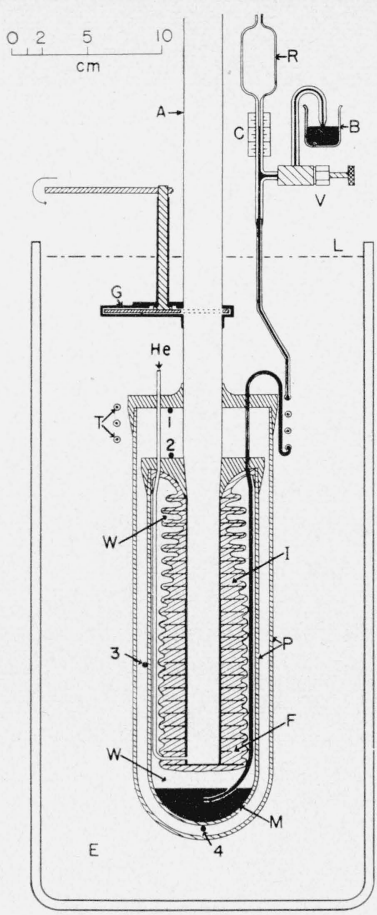

Figure 1. Schematic diagram of ice calorimeter.

A, calorimeter well; B, beaker containing mercury; C, glass capillary; E, ice bath; F, copper vanes; G, gate; I, ice mantle; M, mercury; P, Pyrex containers: $\mathrm{R}$, mercury reservoir; T, mercury "tempering" coil; $\mathrm{V}$, needle valve; $\mathrm{W}$, water; $1,2,3$, and 4 , thermocouple junctions.

recorded when the meniscus passed an arbitrary zero on this scale, the beaker of mercury (B) was replaced by a weighed beaker of mercury, and valve $\mathrm{V}$ opened again. At the end of an experiment, the valve was closed again and the time recorded when the meniscus again passed its zero. The difference in the weights of the beaker gave the weight of mercury sucked into the calorimeter in a measured time. A small correction (perhaps 1 joule) was made for heat leak. The corrected mass of mercury was converted to energy by use of the calibration factor of the ice calorimeter as previously determined [3], $270.46 \mathrm{abs} \mathrm{j} / \mathrm{g}$ of mercury for the "ideal" calorimeter or 270.47 abs $\mathrm{j} / \mathrm{g}$ for the actual calorimeter used. From the duration of the experiment (difference in times at which the mercury meniscus passed the arbitrary zero), the energy was converted into average power.

The values of power calculated in the manner described would be correct if the sample and all other parts in thermal contact with the calorimeter did not change temperature during the experiment. However, as heat is put into the calorimeter, the thickness of the water layer between the ice and the central well with its vanes increases, and as there is flow of heat across this water layer, the temperature drop across this water layer must increase. As a result, the temperatures of the central well and vanes, and the sample with its container, all increase slightly during an experiment, so that part of the heat produced by the sample does not melt ice. This amount of heat depends on the power of the sample, the heat capacities of the various parts, and on the thickness of the water layer at the beginning of the experiment. The analysis of the correction for this heat is given as follows.

Consider a system (such as the radioactive sample plus metal calorimeter well with vanes) separated from ice by a layer of water. Consider also that the thermal contact between sample and calorimeter does not change during an experiment. Let

$\eta=$ the total amount of heat (joules) that has been introduced into the ice calorimeter at any particular time,

$P=$ the power $(\mathrm{j} / \mathrm{sec})$ developed by the sample,

$H=$ the heat capacity $(\mathrm{j} / \mathrm{deg} \mathrm{C})$ of the system (sample plus calorimeter well with vanes),

$A=$ the effective area of contact of the system with ice, $\mathrm{cm}^{2}$,

$K=$ the thermal conductivity of water at $0^{\circ} \mathrm{C}$, $0.0052 \mathrm{w} \mathrm{cm}^{-1} \mathrm{deg}^{-1}$,

$m=$ the average thickness of the water layer, $\mathrm{cm}$,

$F=$ the heat of fusion of ice, $333 \mathrm{j} / \mathrm{g}$.

Then the grams of ice melted $=0 / F=? / 333$.

The volume of water between the ice and the vanes is the same as the volume of ice melted because any void created by the difference in density of ice and water is filled almost instantaneously by water outside the mantle passing through and around the cracks in the ice mantle. Hence, the volume of water layer formed $=$ (specific volume of ice) $(Q / 333)$ $=(1.09) \quad(Q / 333)=0.0033 Q ; \quad m=0.0033(Q / A) ;$ and the temperature difference across the water film $=$ $P m /(0.0052) A=(0.0033 / 0.0052)\left(P Q / A^{2}\right)=0.63(P Q /$ $\left.A^{2}\right)$. Thus the heat stored in the system after $Q$ joules have been introduced (assuming no temperature gradient in the metal system $)=(0.63 H)\left(P Q / A^{2}\right)$, and the heat stored in the water after $Q$ joules have been introduced (assume linear temperature gradient across the film $)=(4.18)(0.0033 Q)(0.63 / 2)\left(P Q / A^{2}\right)=$ $0.0043\left(P Q^{2} / A^{2}\right)$, and the total heat stored $=\left(P / A^{2}\right)$ $\left(0.63 H Q+0.0043 Q^{2}\right)$. If we start an experiment with $Q_{1}$ joules of heat already put into the calorimeter and a steady state of heat flow from the sample to the ice mantle, and end the experiment with $Q_{2}$ joules of heat in the calorimeter, and the same steady state of heat flow, then the difference in heat stored $=\left(P / A^{2}\right)\left[0.63 H\left(Q_{2}-Q_{1}\right)+0.0043\left(Q_{2}^{2}-Q_{1}^{2}\right)\right]$.

The relative error, $E$, is

$$
\begin{aligned}
& E=\frac{P}{A^{2}\left(Q_{2}-Q_{1}\right)}\left[0.63 H\left(Q_{2}-Q_{1}\right)+0.0043\left(Q_{2}^{2}-Q_{1}^{2}\right)\right], \text { or } \\
& E=\frac{P}{A^{2}}\left[0.63 H+0.0043\left(Q_{2}+Q_{1}\right)\right] .
\end{aligned}
$$

If $E$ is plotted against $\left(Q_{2}+Q_{1}\right)$, the slope of the resulting straight line is

$$
\text { Slope }=0.0043 \frac{P}{A^{2}},
$$

and the intercept of this line with the $E$ axis is

$$
\text { Intercept }=0.63 \frac{H P}{A^{2}} \text {. }
$$


This analysis shows that for any given power $P$ of the sample, the slope of this line is dependent only on the effective area of contact $(A)$ of the metal vanes with the ice. This effective area depends, of course, on the length of the sample. The intercept of this line with the relative error axis depends not only upon the area $A$ but also upon the heat capacity, $H$ of the sample-plus-vane system.

For any given sample with a known heat capacity and length, values of $A$ and $H$ can be calculated, using the dimensions and heat capacity of the corresponding portion of the calorimeter well and its system of vanes. It is believed that a better evaluation of $A$ and $H$ can be obtained by electrical calibration experiments, putting in known quantities of electric heat into the calorimeter over a length equivalent to the radioactive samples to be measured. If the heat is distributed in the electrical experiments the same as in the experiments with the radioactive samples, the value of $A$ obtained from the electrical experiments should also be the same. However, the value of $H$ obtained from the electrical experiments differs from that for the radioactive experiments by the difference in heat capacities of the electric heater and the radioactive samples.

The results of the electric calibration experiments are indicated by the circles in figure 2 , which shows the relative error, $E$, plotted against $\left(Q_{1}+Q_{2}\right)$. The best straight line through these circles is labeled "Electric Experiments" and was determined by the method of least squares to be $E=0.000633+2.992 \times$ $10^{-8}\left(Q_{1}+Q_{2}\right)$, where $Q_{1}$ and $Q_{2}$ are expressed in joules. The electric calibration experiments were made with a power of about $1.4 \mathrm{w}$ to correspond approximately to the initial radioactive power of sample 4 , which was the largest of the four samples and therefore had the largest correction for the water layer. The slope of the solid line (electric experiments) indicated that the effective area of contact $(A)$ between the ice and the source of heat was about $420 \mathrm{~cm}^{2}$. This is roughly equivalent to a $9-\mathrm{cm}$ length of the calorimeter well, as compared to an actual length of the electric heater of about $7 \mathrm{~cm}$.

While the value of $A$ obtained from the electric calibration experiments agreed as well as expected with that estimated from the dimensions, the value

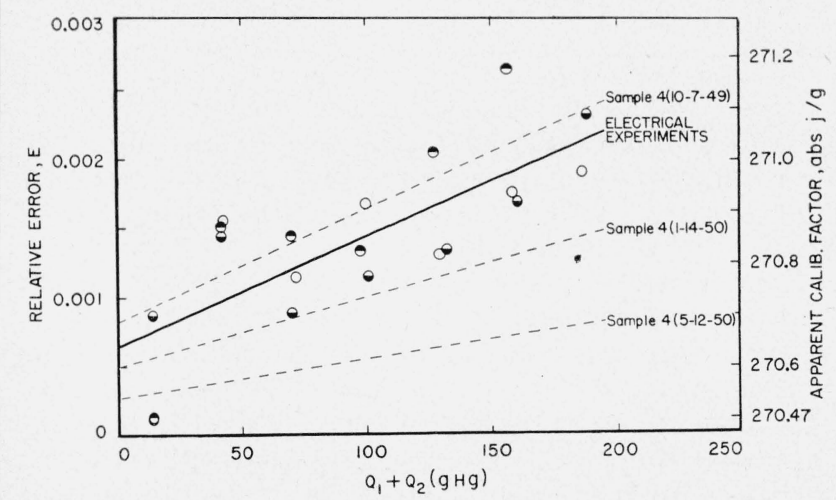

Figure 2. Corrections for water layer in calorimeter. Electrical experiments: $\odot, 10-11-49 ; 0,10-12-49 ; \bigcirc, 10-14-49$. of heat capacity $H$ (after correction for the heat capacity of the heater) corresponded to about a $17-\mathrm{cm}$ length of the calorimeter well, which is considerably more than expected. Some of this difference may be due to the assumption in the theory that the temperature gradient in the copper vanes is negligible. If the position of the line had been calculated entirely on the basis of a 9-cm length of the calorimeter well, it would have the same slope as the line given by the electric experiments but would be shifted to decrease $E$ by almost 0.0003 . Because it is believed that the electric calibration experiments give more reliable values of the effective $A$ and $H$, the solid line in figure 2 was used as basis for the corrections for the experiments with the radioactive samples. The dashed lines shown in the figure for sample 4 were calculated on this basis, as well as corresponding lines (not shown) for the other samples. Values of apparent calibration factor (which is equivalent to $270.47(1+E)$ ) were read from the dashed lines for the corresponding values of $\left(Q_{1}+Q_{2}\right)$.

\section{Results}

The results of the measurements with the four samples are given in table 1 . The mean time of experiment is given, so that all experiments in one group can be corrected for the radioactive decay to bring them all to the same time (noon, EST) on the reference date. The mass of mercury was corrected for the effect of heat leak between the calorimeter and its surroundings (this effect is usually only a few milligrams of mercury). The quantities $Q_{1}$ and $Q_{2}$ are as previously described. Using the quantity $Q_{1}+Q_{2}$, the apparent calibration factor of the ice calorimeter was obtained from figure 2, from the curve for the appropriate sample. The product of this factor and the mass of mercury, divided by the duration of the experiment, gives the power at mean time of experiment. Using an approximate value of the half-life of polonium, this power was converted to power at noon (EST) on the reference date. The deviations from mean power are the deviations of the results of the individual experiments from the mean power of the group of experiments. The values of half-life given in the last column are based on the mean powers and reference dates, and the values indicated in parentheses are the authors' estimated uncertainties of the half-life based on both accidental and systematic errors.

It will be noted that more measurements were made with sample 4 than with the other three samples. This was because sample 4 had the highest power of the four samples, and it was believed that the highest relative calorimetric accuracy could be obtained with this sample, resulting in the best determination of the half-life of polonium. The power of sample 1 was so low that calorimetric errors could account for the low value of half-life calculated. The uncertainty in heat leak of the calorimeter was believed to be about $0.0002 \mathrm{w}$. This uncertainty, when compared with the power measured for sample 1 on May $14,1950(0.05698 \mathrm{w})$, could explain most of the discrepancy with the results with the other 
TABLE 1. Results of experiments

\begin{tabular}{|c|c|c|c|c|c|c|c|c|c|c|c|c|}
\hline $\begin{array}{l}\text { Date of experi- } \\
\text { ment }\end{array}$ & $\begin{array}{l}\text { Mean time of } \\
\text { experiment } \\
\text { EST }\end{array}$ & $\begin{array}{l}\text { Duration } \\
\text { of experi- } \\
\text { ment }\end{array}$ & $\begin{array}{l}\text { Mass of } \\
\text { mercury }\end{array}$ & $Q_{1}$ & $O_{2}$ & $\begin{array}{c}\text { Apparent } \\
\text { calorimeter } \\
\text { factor } \\
270.47(1+E)\end{array}$ & $\begin{array}{l}\text { Power at } \\
\text { mean } \\
\text { time of } \\
\text { experi- } \\
\text { ment }\end{array}$ & $\begin{array}{l}\text { Power at } \\
\text { noon }(\text { EST) } \\
\text { on } \\
\text { reference } \\
\text { date }\end{array}$ & $\begin{array}{c}\text { Reference } \\
\text { date }\end{array}$ & $\begin{array}{l}\text { Devia- } \\
\text { tions } \\
\text { from } \\
\text { mean } \\
\text { power }\end{array}$ & $\begin{array}{l}\text { Mean } \\
\text { power }\end{array}$ & Half-life \\
\hline \multicolumn{13}{|c|}{ Sample 1} \\
\hline $\begin{array}{l}10-3-49 \ldots \ldots \\
10-4-49 \ldots \\
5-3-50 \ldots \\
5-4-50 \ldots \ldots \\
5-14-50 \ldots \\
\end{array}$ & 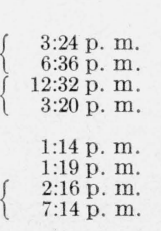 & \begin{tabular}{rl}
\multicolumn{1}{c}{$s e c$} \\
$3 \quad 557.8$ \\
12 & 367.2 \\
9 & 928.0 \\
10 & 126.5 \\
& \\
20 & 354.0 \\
19 & 440.0 \\
21 & 909.5 \\
13 & 948.0
\end{tabular} & $\begin{array}{l}\text { g } \\
\text { 2. } 3048 \\
\text { 7. } 9892 \\
\text { 6. } 3924 \\
\text { 6. } 5205 \\
\\
\text { 4. } 5269 \\
\text { 4. } 2913 \\
\text { 4. } 6221 \\
\text { 2. } 9396\end{array}$ & $\begin{array}{c}g \mathrm{Hg} \\
0 \\
2 \\
10 \\
17 \\
\\
24 \\
29 \\
0 \\
5\end{array}$ & $\begin{array}{c}g \mathrm{Hg} \\
2 \\
10 \\
17 \\
23 \\
29 \\
34 \\
5 \\
8\end{array}$ & $\begin{array}{l}j g^{-1} \\
270.49 \\
270.49 \\
270.50 \\
270.50 \\
270.48 \\
270.48 \\
270.48 \\
270.48\end{array}$ & $\begin{array}{c}a b s w \\
0.17523 \\
.17474 \\
.17417 \\
.17418 \\
\\
.06016 \\
.05971 \\
.05706 \\
.05700\end{array}$ & $\begin{array}{r}a b s w \\
\mathrm{a} 0.17451 \\
.17411 \\
.17419 \\
.17430 \\
\\
.05694 \\
.05680 \\
.05709 \\
.05709\end{array}$ & $16-4-49$ & $\begin{array}{l}\text { percent } \\
\left\{\begin{array}{l}+0.16 \\
-0.07 \\
-0.02 \\
+0.04\end{array}\right. \\
\left\{\begin{array}{l}+0.07 \\
-0.32 \\
+0.19 \\
+0.19\end{array}\right.\end{array}$ & $\begin{array}{l}a b s w \\
0.17423\end{array}$ & b $\begin{array}{c}137.7 \\
( \pm 1.0)\end{array}$ \\
\hline \multicolumn{13}{|c|}{ Sample 2} \\
\hline $\begin{array}{l}10-5-49 \ldots \ldots \\
4-27-50 \ldots \ldots \\
4-28-50\end{array}$ & $\left\{\begin{array}{c}11: 10 \text { a. m. } \\
\text { 12:45 p. m. } \\
\text { 2:15 p. m. } \\
\text { 1:48 p. m. } \\
\text { 1:00 p. m. }\end{array}\right.$ & $\begin{array}{rl}6 & 168.5 \\
5 & 224.0 \\
5 & 478.0 \\
& \\
16 & 514.9 \\
17 & 999.8\end{array}$ & $\begin{array}{l}\text { 9. } 1630 \\
\text { 7. } 7486 \\
8.1294 \\
\\
\text { 8. } 8470 \\
9.5623\end{array}$ & $\begin{array}{l}23 \\
32 \\
40 \\
\\
24 \\
33\end{array}$ & $\begin{array}{l}32 \\
40 \\
48 \\
\\
33 \\
43\end{array}$ & $\begin{array}{l}270.56 \\
270.57 \\
270.58 \\
270.50 \\
270.50\end{array}$ & $\begin{array}{r}0.40190 \\
.40133 \\
.40154 \\
\\
.14491 \\
.14370\end{array}$ & $\begin{array}{r}0.40183 \\
.40139 \\
.40173 \\
\\
.14425 \\
.14373\end{array}$ & $\begin{array}{l}10-5-49 \\
4-28-50\end{array}$ & $\begin{array}{l}\left\{\begin{array}{l}+0.04 \\
-0.06 \\
+0.02\end{array}\right. \\
\left\{\begin{array}{l}+0.18 \\
-0.18\end{array}\right.\end{array}$ & $\left.\begin{array}{c}0.40165 \\
0.14399\end{array}\right\}$ & b $\begin{aligned} & 138.52 \\
&( \pm 0.4)\end{aligned}$ \\
\hline \multicolumn{13}{|c|}{ Sample 3} \\
\hline $\begin{array}{l}10-8-49 \ldots \ldots \\
4-19-50 \ldots \ldots \\
4-20-50 \ldots \ldots\end{array}$ & $\begin{array}{l}\left\{\begin{array}{r}1: 24 \text { p. m. } \\
2: 45 \text { p. m. } \\
4: 06 \text { p. m. }\end{array}\right. \\
\begin{array}{r}1: 49 \text { p. } \mathrm{m} \\
11: 35 \text { p. } \mathrm{m} \\
2: 31 \text { p. } \mathrm{m} .\end{array}\end{array}$ & $\begin{array}{rl}5 & 134.4 \\
5 & 207.5 \\
4 & 576.2 \\
& \\
12 & 692.3 \\
10 & 313.6 \\
10 & 808.6\end{array}$ & $\begin{array}{r}12.2025 \\
12.3623 \\
10.8695 \\
11.4817 \\
9.2898 \\
9.7279\end{array}$ & $\begin{array}{r}0 \\
12 \\
24 \\
\\
0 \\
11 \\
20\end{array}$ & $\begin{array}{l}12 \\
24 \\
35 \\
11 \\
20 \\
30\end{array}$ & $\begin{array}{l}270.58 \\
270.61 \\
270.63 \\
270.51 \\
270.52 \\
270.52\end{array}$ & $\begin{array}{r}0.643 \curvearrowleft 6 \\
.64241 \\
.64280 \\
.24471 \\
.24367 \\
.24347\end{array}$ & $\begin{array}{r}0.64323 \\
.64278 \\
.64335 \\
.24358 \\
.24365 \\
.24360\end{array}$ & $10-8-49$ & $\begin{array}{l}\left\{\begin{array}{r}+0.02 \\
-0.05 \\
+0.04\end{array}\right. \\
\left\{\begin{array}{r}-0.01 \\
+0.02 \\
0.00\end{array}\right.\end{array}$ & $\left.\begin{array}{l}0.64312 \\
0.24361\end{array}\right\}$ & $\begin{array}{r}138.52 \\
\text { b }( \pm 0.23)\end{array}$ \\
\hline \multicolumn{13}{|c|}{ Sample 4} \\
\hline $10-6-49 \ldots$ & $\begin{array}{l}\text { 12:55 p. m. } \\
\text { 1:35 p. m. } \\
\text { 1:28 p. m. } \\
2: 07 \text { p. m. } \\
\text { 2:57 p. m. } \\
\text { 3:3 p. m. } \\
\text { 4:28 p. m. } \\
\text { 5:14 p. m. } \\
\text { 6:00 p. m. }\end{array}$ & $\begin{array}{l}2634.7 \\
2766.9 \\
2 \quad 622.8 \\
2676.2 \\
2733.6 \\
277.2 \\
2736.5 \\
2689.3 \\
2879.7\end{array}$ & $\begin{array}{l}\text { 14. } 0020 \\
14.7066 \\
13.8785 \\
14.1607 \\
14.4582 \\
14.3735 \\
14.4643 \\
14.1840 \\
15.2113\end{array}$ & $\begin{array}{r}28 \\
42 \\
0 \\
14 \\
28 \\
42 \\
57 \\
71 \\
86\end{array}$ & $\begin{array}{r}42 \\
57 \\
14 \\
28 \\
42 \\
57 \\
71 \\
86 \\
101\end{array}$ & $\begin{array}{l}270.84 \\
270.91 \\
270.72 \\
270.78 \\
270.84 \\
270.91 \\
270.97 \\
271.03 \\
271.10\end{array}$ & $\begin{array}{l}1.43937 \\
1.43994 \\
1.43251 \\
1.43279 \\
1.43249 \\
1.43306 \\
1.43226 \\
1.42948 \\
1.43202\end{array}$ & $\begin{array}{l}1.43307 \\
1.43382 \\
1.43296 \\
1.43345 \\
1.43338 \\
1.43423 \\
1.43361 \\
1.43105 \\
1.43382\end{array}$ & $10-7-49$ & $\begin{array}{l}-0.01 \\
+0.04 \\
-0.02 \\
+0.01 \\
+0.01 \\
+0.07 \\
+0.02 \\
-0.15 \\
+0.04\end{array}$ & 1. 43327 & $\begin{array}{l}138.39 \\
\text { b }( \pm 0.14)\end{array}$ \\
\hline $1-14-50$ & $\begin{array}{l}\text { 11:00 a. m. } \\
\text { 11:54 a. m. } \\
\text { 12:50 p. m. } \\
\text { 1:44 p. m. } \\
\text { 2:35 p. m. } \\
3: 28 \text { p. m. }\end{array}$ & $\begin{array}{ll}3 & 170.1 \\
3 & 345.9 \\
3 & 359.8 \\
3 & 067.7 \\
3 & 115.1 \\
3 & 178.3\end{array}$ & $\begin{array}{r}10.2320 \\
10.7884 \\
10.8281 \\
9.8837 \\
10.0448 \\
10.2384\end{array}$ & $\begin{array}{l}10 \\
20 \\
31 \\
42 \\
52 \\
62\end{array}$ & $\begin{array}{l}20 \\
31 \\
42 \\
52 \\
62 \\
72\end{array}$ & $\begin{array}{l}270.64 \\
270.67 \\
270.70 \\
270.73 \\
270.74 \\
270.78\end{array}$ & $\begin{array}{r}0.87353 \\
.87274 \\
.87242 \\
.87225 \\
.87302 \\
.87228\end{array}$ & $\begin{array}{l}0.87335 \\
.87272 \\
.87257 \\
.87256 \\
.87349 \\
.87292\end{array}$ & $1-14-50$ & $\begin{array}{l}+0.05 \\
-0.03 \\
-0.04 \\
-0.04 \\
+0.06 \\
+0.00\end{array}$ & 0.87294 & 138.40 \\
\hline $5-12-50$ & $\begin{array}{r}\text { 10:04 a. m. } \\
\text { 12:25 p. m. } \\
\text { 2:46 p. m. } \\
\text { 5:00 p. m. } \\
\text { 6:55 p. m. } \\
\text { 8:43 p. m. }\end{array}$ & 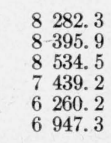 & $\begin{array}{l}14.8070 \\
15.0148 \\
15.2193 \\
13.2613 \\
11.1775 \\
12.3852\end{array}$ & $\begin{array}{r}3 \\
18 \\
33 \\
48 \\
61 \\
72\end{array}$ & $\begin{array}{l}18 \\
33 \\
48 \\
61 \\
72 \\
85\end{array}$ & $\begin{array}{l}270.56 \\
270.58 \\
270.61 \\
270.63 \\
270.64 \\
270.66\end{array}$ & $\begin{array}{l}.48370 \\
.48389 \\
.48257 \\
.48243 \\
.48322 \\
.48252\end{array}$ & $\begin{array}{l}.48350 \\
.48393 \\
.48284 \\
.48293 \\
.48391 \\
.48339\end{array}$ & $5-12-50$ & $\begin{array}{r}+0.00 \\
+0.10 \\
-0.12 \\
-0.10 \\
+0.09 \\
0.00\end{array}$ & 0.48342 & \\
\hline
\end{tabular}

a Experiment weighted one-third because of short duration of experiment.

b Figure given for uncertainty based upon authors' estimate of both accidental and systematic errors.

samples having higher power because it would require an increase of only $0.0003 \mathrm{w}$ in the value observed on May 14 to agree with the other samples.

It is interesting to note the corresponding effects of an uncertainty of $0.0003 \mathrm{w}$ on the other samples having higher powers. With samples 2 and 3 , this uncertainty in the May values would result in halflife uncertainties of about 0.21 percent ( 0.29 day) and 0.12 percent $(0.17$ day), respectively. With sample 4 , however, the same power uncertainty in the values on January 14 results in only 0.04 percent $(0.06$ day) uncertainty in the over-all half-life. The uncertainty in heat leak is probably the largest error in the measurements with samples 1,2 , and 3 . With sample 4 , however, the heat leak uncertainty is probably comparable with all other errors. In addition, sample 4 was observed at an intermediate date (0.7 half-life) in an effort to detect any change in the decay constant with time.

The measurements with the four samples agree within \pm 0.1 percent, or $0.0003 \mathrm{w}$, whichever is the larger. The slightly different half-life values on sample 4 for the two different periods are not significant because the difference is much less than the experimental error. There is no significant evidence, therefore, of a change in the decay constant, such as would occur either if the polonium was contaminated with radioactive impurities having values of half-life different from polonium, or if some secondary chemical or nuclear reaction produced heat that was not 
directly proportional to the radioactive energy of the polonium sample. In addition, the polonium samples used were of a purity that should have precluded the possiblity of appreciable contamination by other radioactive elements. The polonium had been purified both by distillation and by electrodeposition on platinum foils from dilute nitric-acid solution of polonium nitrate. Of course, the stable lead isotope formed from the decay of polonium was present but could not affect the results of this investigation.

The best value of the half-life of polonium was estimated from the two values for sample 4, giving more weight to the earlier value, where the sample had a larger power. On this basis, the authors believe that the best value of the half-life derived from these measurements is 138.39 days. It is believed that the calorimetric uncertainties (based upon both accidental and systematic errors) in the experiments may result in an error in this value of \pm 0.1 percent (0.14 day).

The results of these measurements are in agreement with the value reported by Beamer and Easton [1] of 138.3 days \pm 0.1 percent, determined calorimetrically by another method.

\section{References}

「1] William H. Beamer and William E. Easton, J. Chem. Phys. 17, 1298 (1949).

[2] Swietoslawski, Microcalorimetry, p. 66 (Reinhold Publishing Corporation, New York, N. Y., 1946).

「3] Defoe C. Ginnings, Thomas B. Douglas, and Anne F. Ball, $J$. Research NBS 45, 23 (1950) RP2110.

[4] D. C. Ginnings and R. J. Corruccini, J. Research NBS 38, 593 (1947) RP1797.

Washington, July 15, 1952. 